\title{
Evolution of stress intensity factors in mixed mode with presence of mismatch effect
}

\author{
Tawfik Tamine ${ }^{1, a}$, NABil Kazi Tani $^{2}$ And GuY Pluvinage ${ }^{3}$ \\ 1 Laboratoire LCGE, Faculté de Génie Mécanique, USTO M.B, 1505 EL M’Naouer, 31000 Oran, Algérie \\ 2 Laboratoire LM2SC, Faculté d'Architecture et de Génie Civil, USTO M.B, 1505 El M'Naouer, 31000 Oran, Algérie \\ 3 Fiabilité Mécanique Conseil, 57530 Silly sur Nied, France
}

Received 6 February 2011, Accepted 13 August 2012

\begin{abstract}
In this study, numerical models based on finite-element method are developed for several applications of fracture mechanics. The use of cracked specimens formed by different material properties has allowed us to analyse the effect of the crack position to the interface and to have a well understanding of mismatch effect for the case of mixed mode of fracture. In other hand, we have noticed that it is very interesting to see the effect of the interface position and loading for the case of symmetrically cracked ring specimen under compression loading.
\end{abstract}

Key words: Crack / interface / bi-material / mixed mode / stress intensity factor / mismatch effect

Résumé - Évolution des facteurs d'intensité de contraintes en mode mixte en présence de l'effet mismatch. Dans cette étude, des modélisations numériques par la méthode des éléments-finis ont été développées pour des applications en mécanique de la rupture. L'utilisation d'éprouvettes fissurées constituées de matériaux de propriétés mécaniques différentes ont permis de mettre en exergue l'influence de la position de la fissure par rapport à l'interface et de comprendre l'effet du mismatch en mode mixte. D'autre part, il a été intéressant de voir aussi l'influence de la position de l'interface par rapport au chargement pour des fissures symétriques dans une structure en anneau.

Mots clés : Fissure / interface / bi-materiaux / mode mixte / facteur d'intensite de contraintes / effet mismatch

\section{Introduction}

Actually, most of the structures and mechanical components are formed within at least two dissimilar materials. For almost all cases, the use of heterogeneous materials is due to strength issues, protection against corrosion, rubbing, etc. The difficulty is to describe the stress field which is perturbed at the crack tip near the interface. So many researchers have tried to analyse stress fields and to evaluate fracture parameters of cracked bi-material specimens. In the mid 1960, various research works have been carried out by Erdogan [1], Rice and Sih [2] to verify William's [3] finding of complex singularities and oscillating stresses near the crack tip. The well know Dundurs [4] parameters were used by many researchers to predict the stress intensity factors for bimaterials when the crack was perpendicular to the interface. Comninou [5] resolved the crack interface problem by assuming that there is a small

${ }^{a}$ Corresponding author: tamine63@yahoo.fr contact zone near the crack tip which is extremely small. For interface crack in tension, the contact zone model provides a contact zone of the order $10^{-4}$ of the crack length. Recently, some formulations and new techniques were developed such as Wang and Stahle [6], Marur and Tippur [7] who have solved the interfacial crack problems in bi-material plates analytically by developing the stress field relationships as analytical series. Stress intensity factor for crack in bi-material interface has been studied by Bjerken and Persson [8] and Ikeda and Sun [9]. The first authors have applied integral method for the determination of complex relationships of stress intensity factors, the second authors have used the virtual crack extension technique for cracked bi-material specimens under thermal loading. Kang Yilan and Lu Hua [10] have developed a calculation procedure for displacement field near the crack tip emanating from interface. Experimental methods have been used by Jiang et al. [11] to describe the evolution of J-R curves and to study the propagation of 


\section{Nomenclature}

\begin{tabular}{|ll|}
\hline$K\left[\mathrm{MPa} \cdot \mathrm{m}^{1 / 2}\right]$ & Stress intensity factor \\
$K_{1}\left[\mathrm{MPa} \cdot \mathrm{m}^{1 / 2}\right]$ & Stress intensity factor for the first mode of fracture \\
$K_{2}\left[\mathrm{MPa} \cdot \mathrm{m}^{1 / 2}\right]$ & Stress intensity factor for the second mode of fracture \\
$\varepsilon$ & Bi-elastic constant of material \\
$E_{j}$ & Young modulus of material $j$ \\
$\nu_{j}$ & Poisson ratio of material $j$ \\
$G_{j}$ & Shear modulus of material $j$ \\
$u^{i}$ & Displacement of node $i$ with respect to $x$ axis \\
$v^{i}$ & Displacement of node $i$ with respect to $y$ axis \\
$s$ & Distance between nodes $a$ and $c$ or $a$ and $e$ \\
$a[\mathrm{~m}]$ & Crack length \\
$W[\mathrm{~m}]$ & Plate wide \\
$K_{\mathrm{eq}}\left[\mathrm{MPa} \cdot \mathrm{m}^{1 / 2}\right]$ & Equivalent stress intensity factor \\
$\bar{K}_{\mathrm{eq}}\left[\mathrm{MPa} \cdot \mathrm{m}^{1 / 2}\right]$ & Normalized equivalent stress intensity factor \\
$\bar{K}_{\mathrm{eqA}}\left[\mathrm{MPa} \cdot \mathrm{m}^{1 / 2}\right]$ & Normalized equivalent stress intensity factor at crack tip A \\
$\bar{K}_{\mathrm{eqB}}\left[\mathrm{MPa} \cdot \mathrm{m}^{1 / 2}\right]$ & Normalized equivalent stress intensity factor at crack tip B \\
$R_{1}[\mathrm{~m}]$ & Internal radius of cracked ring specimen \\
$R_{2}[\mathrm{~m}]$ & External radius of cracked ring specimen \\
$\sigma_{\mathrm{g}}[\mathrm{MPa}]$ & Global applied stress \\
$\sigma_{\mathrm{g} 1}[\mathrm{MPa}], \sigma_{\mathrm{g} 2}[\mathrm{MPa}]$ & Applied stress in y direction for material 1 and 2 respectively \\
$\alpha\left[^{\circ}\right]$ & Inclination angle of interface with respect to $x$ axis \\
$\theta\left[{ }^{\circ}\right]$ & Inclination angle of the crack with respect to $x$ axis \\
$\mathrm{SIF}$ & Stress Intensity Factor \\
$\mathrm{RGB}$ & Red Green Blue \\
$\mathrm{PSM} 1 / \mathrm{Al}$ & Polycarbonate/aluminium \\
\hline
\end{tabular}

cracks emanating from interface of bi-material specimens under three points flexion loading. Another experimental method based on RGB photoelasticity has been carried out by Cirello and Zuccarelo [12] to analyse the propagation of cracks perpendicular to interface of bi-material plates. Numerical models have been developed by Madani et al. [13], Ouinas et al. [14] and Kazi Tani et al. [15] to show the effect of interfaces on crack propagation in bi-material specimen. The restitution energy rate $G$ and the stress intensity factor (SIF) have been determined by those authors for several crack positions between dissimilar materials.

In this present paper, two important points are discussed; the first one is to describe the effect of mixed mode on the decreased curves of stress intensity factor obtained by Cirello and Zuccarelo using RGB photoelasticity technique [12] and confirmed numerically by Kazi Tani et al. [15] on bi-material plates PSM1/Al polycarbonate/aluminium, for the first mode of fracture. The second point concerns the influence of the interface position and loading direction on the stress field near the crack tip of bi-material ring specimen where cracks are symmetrically located.

\section{Stress intensity factor at bi-material interface}

For a crack of $2 a$ length located at the interface between two dissimilar materials subjected to a uniform tensile load, the complex relationship of the stress intensity factors are given by Rice [16] as:

$$
K_{1}+i K_{2}=\sigma_{y}(1+2 i \varepsilon)(2 a)^{-i \varepsilon}(\pi a)^{0.5}
$$

Bi-elastic constant is given by:

$$
\varepsilon=\frac{1}{2 \pi} \ln (\gamma)
$$

with

$$
\gamma=\frac{G_{1}+\kappa_{1} G_{2}}{G_{2}+\kappa_{2} G_{1}}
$$

where

$$
\begin{aligned}
& \kappa_{j}=3-4 \nu_{j} \quad \text { in plane strain; } \\
& \kappa_{j}=\left(3-\nu_{j}\right) /\left(1+\nu_{j}\right) \quad \text { in plane stress; }
\end{aligned}
$$

and

$$
G_{j}=\frac{E_{j}}{2\left(1+\nu_{j}\right)}
$$

$G_{j}, E_{j}$ and $\nu_{j}$ are respectively shear modulus, Young modulus and Poisson ratio of material $j$.

For the case where the crack is at the interface (Fig. 1), Tan and Gao [17], Emin Ergun et al. [18] expressed SIF relationships from displacement correlation method.

From displacements values of nodes $a, b, c, d, e$ obtained by finite-element method, it is possible to express 


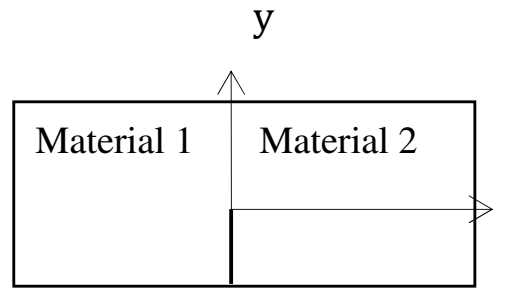

(a)

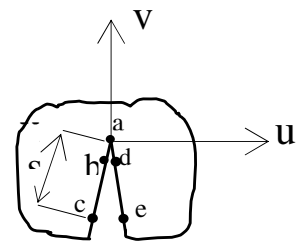

(b)
Fig. 1. Interface crack in bi-material specimen.

opening and shear fracture modes by the following equations given by references $[17,18]$ :

$$
\begin{aligned}
& K_{1}=\sqrt{\frac{2 \pi}{s}}\left[C_{1}\left(-v^{e}+4 v^{d}-3 v^{a}\right)-C_{2}\left(-v^{c}+4 v^{b}-3 v^{a}\right)\right] \\
& K_{2}=\sqrt{\frac{2 \pi}{s}}\left[C_{1}\left(-u^{e}+4 u^{d}-3 u^{a}\right)-C_{2}\left(-u^{c}+4 u^{b}-3 u^{a}\right)\right]
\end{aligned}
$$

$s$ is the distance between nodes $a$ and $c$ or $a$ and $e$. $u^{i}$ and $v^{i}$ are respectively the node displacements with respect to $x$ and $y$ axis.

$$
\begin{aligned}
& C_{1}=\frac{(1+\gamma) \zeta}{\cosh (\pi \varepsilon)} \frac{G_{1}}{\kappa_{1} e^{\pi \varepsilon}+\gamma e^{-\pi \varepsilon}} \\
& C_{2}=\frac{(1+\gamma) \zeta}{\cosh (\pi \varepsilon)} \frac{G_{1}}{\kappa_{2} \gamma e^{-\pi \varepsilon}+e^{\pi \varepsilon}}
\end{aligned}
$$

with

$$
\zeta=\left[\frac{1}{4}+\varepsilon^{2}\right]^{1 / 2}
$$

\section{Numerical examples}

\subsection{Mismatch effect in mixed mode}

To have a well understanding of mismatch effect, we have taken back the numerical example which was in analyzed in references $[12,15]$. In our case, an inclined central crack of $2 a$ length with an angle $\theta$ from horizontal axis $x$ as shown in Figure 2 is studied. The cracked bimaterial formed by polycarbonate PSM-1 (Material 1) and aluminium (Material 2) with dimensions equal to are $W_{2} / W_{1}=1.5, H / W_{1}=12.5, W_{1}=12 \mathrm{~mm}$ and the thickness is equal to $5 \mathrm{~mm}$. The bi-material plate is subjected to a tensile load in $y$ direction, $\sigma_{\mathrm{g}}=20 \mathrm{MPa}$. It is possible to determine the applied stress on each material by applying the principle of matrix-fiber system where the applied stress is given by [12] as follows:

$$
\sigma_{\mathrm{g}}=\sigma_{\mathrm{g} 1}=\left[\nu_{1}+\left(1-\nu_{1}\right) \frac{E_{2}}{E_{1}}\right]
$$

If we suppose that both materials 1 and 2 behave elastically and the global deformation is the same for each side of material 1 and 2 , then we can write:

$$
\frac{\sigma_{\mathrm{g} 1}}{\sigma_{\mathrm{g} 2}}=\frac{E_{1}}{E_{2}}
$$

From Equations (10) and (11), we can split the total stress $\sigma_{Y}$ into two components $\sigma_{\mathrm{g} 1}$ and $\sigma_{\mathrm{g} 2}$.

Numerical model carried out by using ANSYS software finite-element have allowed us to determine the displacement field and stress intensity factors for mode I and mode II. The solution of the problem has been calculated by using 8 node quadratic elements in plane stress by computing $K_{1}, K_{2}$ from the nodal displacements on opposite sides of the crack plane [19] with singular element size around $5 \%$ of crack length. For symmetric configuration of the specimen, only the quarter of the plate is considered in finite-elements model (Fig. 2)

The numerical results of stress intensity factors obtained in mode I and II are plotted in Figures 3a and 4. For well representing those results, the values of SIF are normalized by $K_{0}=\sigma_{\mathrm{g} 1} \sqrt{\pi a}$. Results of $\bar{K}_{\mathrm{I}}$ in Figure 3a are compared with the case of mode I Figure $3 \mathrm{~b}$ obtained by $[15]$.

According to the results plotted in Figures 3a and 4, we have noticed that for the most of $\theta$ inclinaison angles of crack, the normalized stress intensity factors $\bar{K}_{\mathrm{I}}$ and $\bar{K}_{\text {II }}$ are decreasing as the crack becomes longer. In the case of mode I, the decreased values are more significant when $\theta$ varies between $0^{\circ}$ and $30^{\circ}$. The values of $\bar{K}_{\text {I seems }}$ constant for the case when $\theta>45^{\circ}$. This decreased curve is well described by [15] for a central crack in mode I. The same evolution has been noticed for mode II (Fig. 4) except for the case $\theta=10^{\circ}$ where the normalized SIF increases with crack lengths $a / W>0.6$.

In order to compare the numerical results with first mode of fracture mode I $(\theta=0)$ [15], we have represented in Figure 5, the equivalent stress intensity factor for the mixed mode $\bar{K}_{\text {eq }}$, which it is given by the following relationship:

$$
\bar{K}_{\mathrm{eq}}=\sqrt{\bar{K}_{\mathrm{I}}^{2}+\bar{K}_{\mathrm{II}}^{2}}
$$

In Figure 5 , the equivalent stress intensity factor $\bar{K}_{\text {eq }}$ decreases when inclination angle $\theta$ varies between $0^{\circ}$ and $45^{\circ}$. For angles $\theta=60^{\circ}$ and $75^{\circ}, \bar{K}_{\text {eq }}$ values seem to be constant and do not depend on the crack length. This can be explained by the presence of mismatch effect which is more significant when the crack tip is near the interface. The presence of the crack in weakest material and mismatch effect yield a "closing" bridging stress intensity factor that decreases the stress intensity factor resulting from external loading, especially when the crack tip is close to the interface.

Elsewhere, we have taken back the same model by changing the position of materials where material 1 is Aluminium and material 2 is PSM-1.

The numerical results of stress intensity factors in mode I and II are shown in Figures 6 and 7 . 


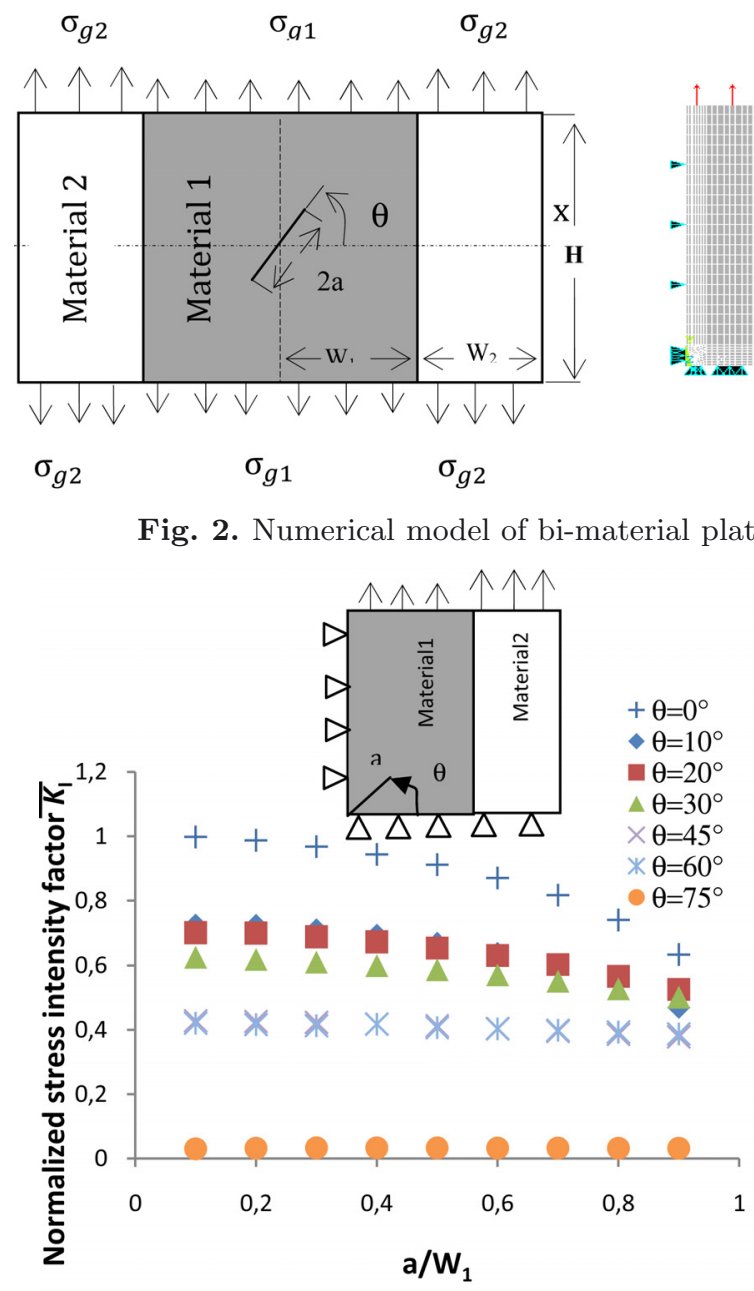

(a)

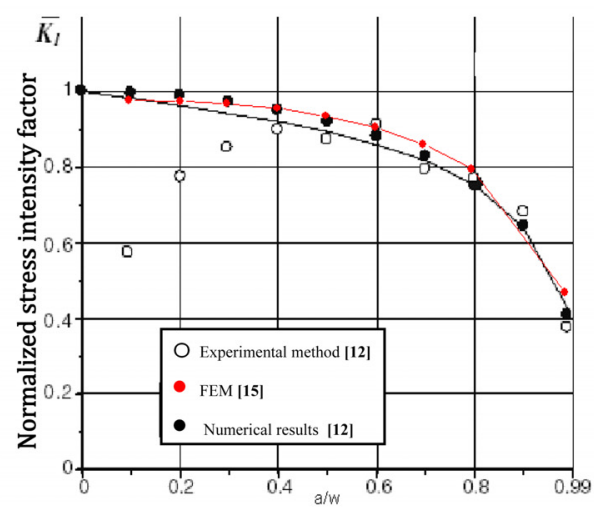

(b)

Fig. 3. (a) Evolution of normalized stress intensity factor $\bar{K}_{\mathrm{I}}$ with crack length and inclinaison angle $\theta \mathrm{g}, E_{1} / E_{2}=0.047$. (b) Evolution of normalized stress intensity factor in mode I $\left(\theta=0^{\circ}\right)$ [15].

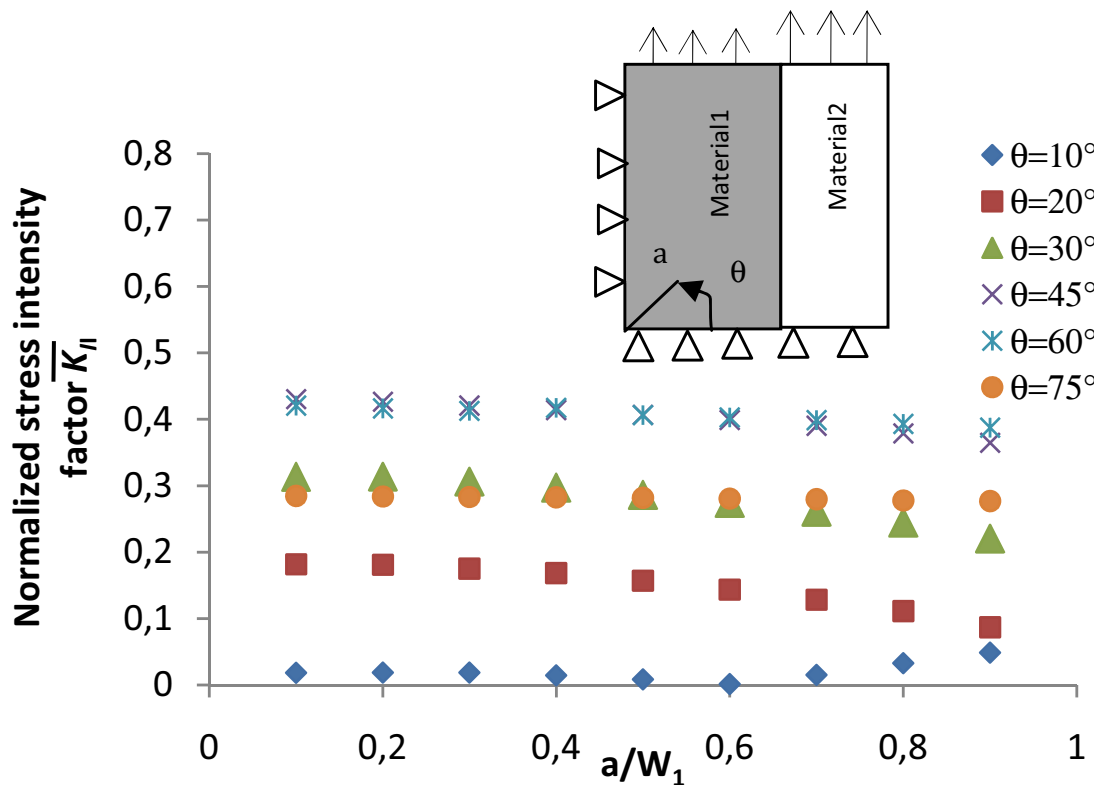

Fig. 4. Evolution of normalized stress intensity factor $\bar{K}_{\mathrm{II}}$ with crack length and inclinaison angle $\theta, E_{1} / E_{2}=0.047$. 


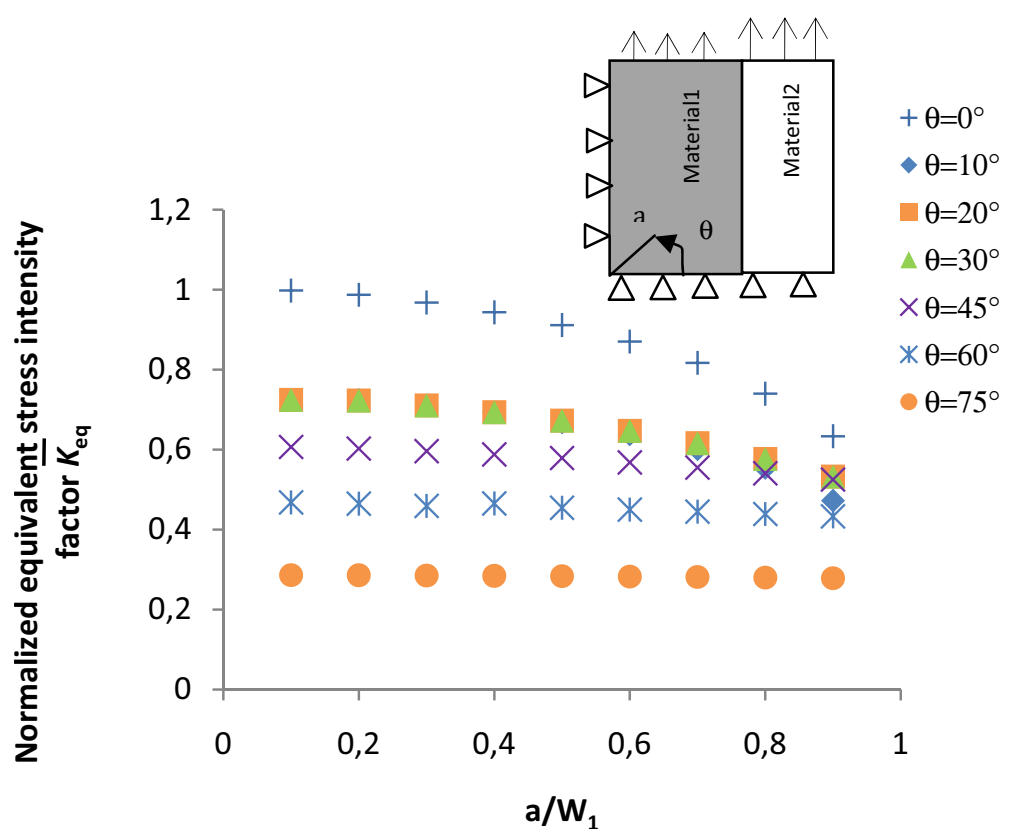

Fig. 5. Evolution of normalized equivalent stress intensity factor $\bar{K}_{\mathrm{eq}}$ with crack length and inclinaison angle $\theta, E_{1} / E_{2}=0.047$.

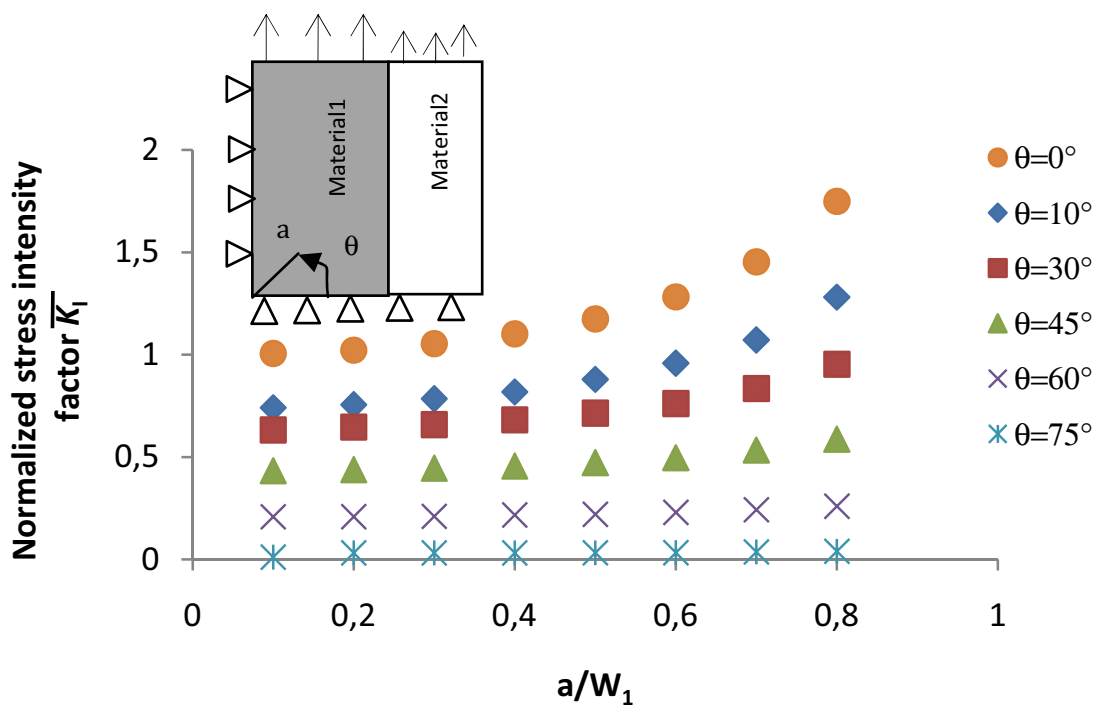

Fig. 6. Evolution of normalized stress intensity factor $\bar{K}_{\mathrm{I}}$ with crack length and inclination angle $\theta, E_{1} / E_{2}=21.276$.

In Figure 6 , the increasing curves of $\bar{K}_{\mathrm{I}}$ are more significant when $\theta$ angles vary between $\theta=0^{\circ}$ and $\theta=45^{\circ}$. For $\theta=60^{\circ}$ and $75^{\circ}$, the values of normalized SIF are very close.

In Figure 7, which represents the second mode we notice that $\bar{K}_{\text {II }}$ values increase with the crack length for all angles except $\theta=10^{\circ}$ where $\bar{K}_{\text {II }}$ data finishes by decreasing from $a / W_{1}>0.6$.

To have a well understanding of the influence of the mixed mode $(\mathrm{I}+\mathrm{II})$, we have represent the $\bar{K}_{\text {eq }}$ data in Figure 8.

Graphs in Figure 8 show the increase of normalized stress intensity factor with crack length and this for all the inclination angles of the crack except for $\theta=75^{\circ}$ where $\bar{K}_{\text {eq }}$ remains constant for all geometric ratios $a / W_{1}$.
From the results, the influence of the interface on the evolution of $\bar{K}_{\mathrm{eq}}$ is significant for $a / W_{1}>0.3$ and the slope evolution of graphs seems higher especially for inclination angles between $\theta=0^{\circ}$ and $\theta=60^{\circ}$. This slope is less pronounced for $\theta>60^{\circ}$.

These results show that the increase of $\bar{K}_{\text {eq }}$ with the ratio of crack size to the distance to the interface depends strongly on the ratio of Young's moduli of the two materials: under uniform applied displacement, $\bar{K}_{\text {eq }}$ decreases when the crack inclination becomes closer to the interface direction if the crack is located in the weakest material.

Also it is important to insist that the width ratio $W_{1} / W_{2}$ has no effect on the $\bar{K}_{\text {eq }}$ results and this is connected to the boundary conditions which states that $\frac{\sigma_{1}}{\sigma_{2}}=\frac{E_{1}}{E_{2}}$. 


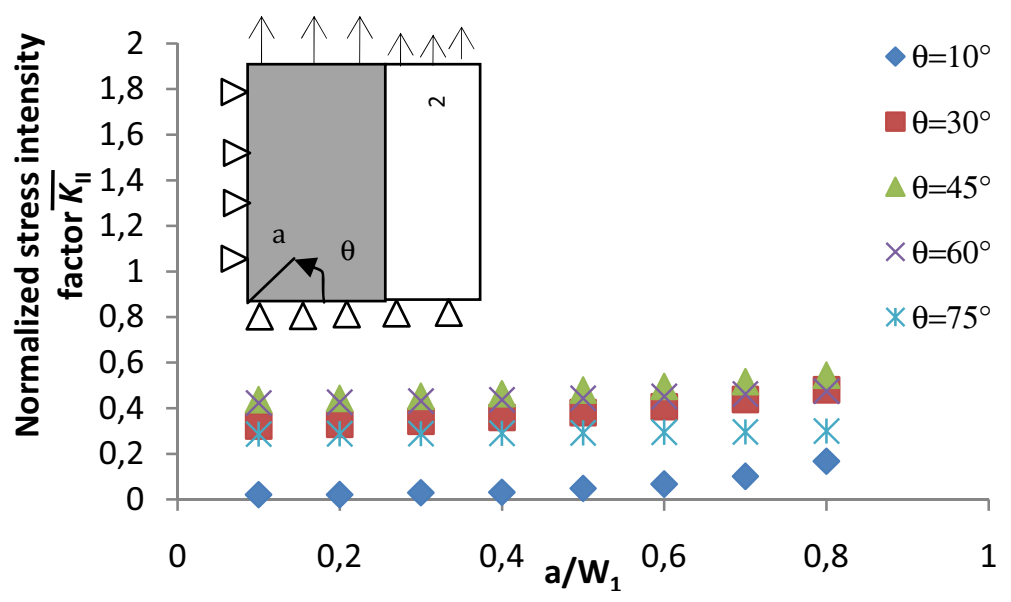

Fig. 7. Evolution of normalized stress intensity factor $\bar{K}_{\mathrm{II}}$ with crack length and inclination angle $\theta, E_{1} / E_{2}=21.276$.

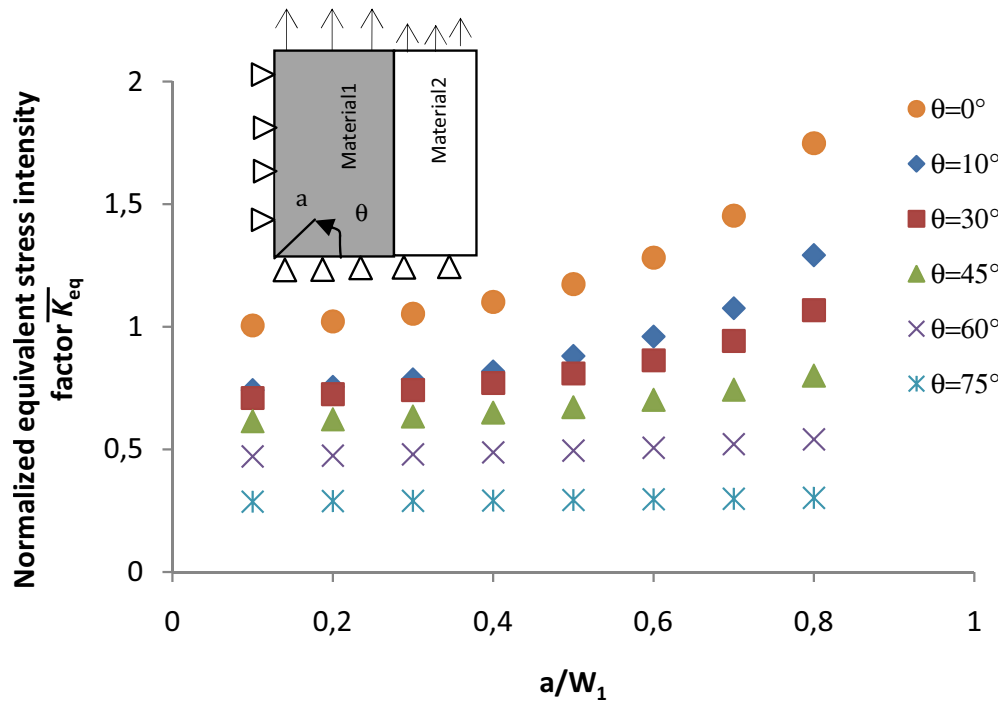

Fig. 8. Evolution of normalized equivalent stress intensity factor $\bar{K}_{\text {eq }}$ with crack length and inclination angle $\theta, E_{1} / E_{2}=21.276$.

The mismatch effect concerns also the mixed mode of fracture and depends on crack inclinaison angle. It is important to established that normalized equivalent stress intensity factors values in mixed mode will never exceed the ones obtained for the case of the first mode of fracture, i.e. $\theta=0^{\circ}$.

The fact to consider geometric ratio of specimen $W_{1} / W_{2}=1.5$ in mixed mode don't have any influence on the decreasing tendency of the stress intensity factor which is confirmed by [15] for geometric ratio $W_{1} / W_{2}=1$ in mode I.

\subsection{Symmetric cracks in bi-material ring specimen}

\subsubsection{Influence of interface position on the stress intensity factors}

Figure 9 shows a bi-material cracked ring specimen where the edge cracks are located symmetrically with a length and subjected to a compression load F. Mechanical properties of material 1 are: Young modulus
$E_{1}=3050 \mathrm{MPa}$, Poisson ratio $\nu_{1}=0.39$ and for material 2, we have: Young modulus $E_{2}=64300 \mathrm{MPa}$, Poisson ratio $\nu_{2}=0.33$.

Geometric ratio of the crack is defined by $a /\left(R_{2}-R_{1}\right)$ which varies between 0.1 and 0.7 , radius ratio of ring is $R_{2} / R_{1}=4.0$ and the thickness of the ring specimen is equal to $5 \mathrm{~mm}$.

Numerical model of the cracked specimen is considered with a flat edge where a pressure of $P=F / S$ is applied ( $S$ is the flat cross section). The resolution is performed in plane stress using 8 nodes quadratic elements, (Fig. 9). The global stress for this case can be expressed with the following relationship given by [20]:

$$
\sigma_{\mathrm{g}}=\frac{3 F\left(R_{2}+R_{1}\right)}{\pi B\left(R_{2}-R_{1}\right)^{2}}
$$

The calculation of the normalized stress intensity factors is done by using the formulation $K_{0}=\sigma_{g} \sqrt{\pi a}$ at crack tips A and B. Then, we obtain on the following graphs, Figures 10 and 11 respectively for mode I and mode II at crack tip A. 

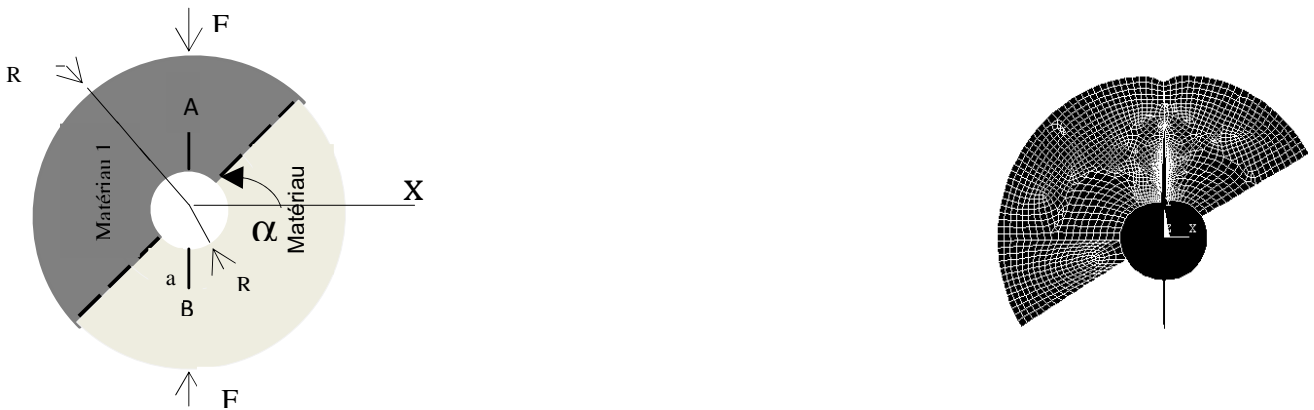

a/ Compression loading of cracked specimen b/ FEM meshing of cracked specimen

Fig. 9. Numerical model of bi-material ring with symmetric edge cracks.

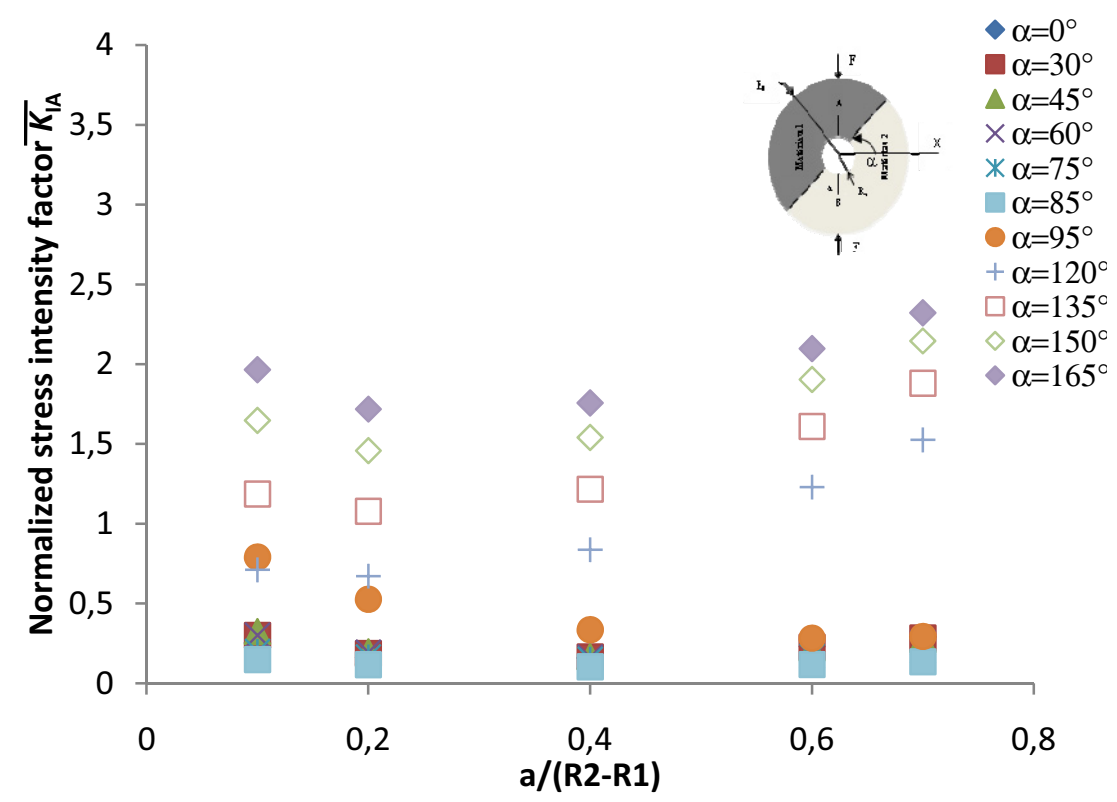

Fig. 10. Evolution of normalized stress intensity factor in mode I (opening) at crack tip A, $E_{1} / E_{2}=0.047$.

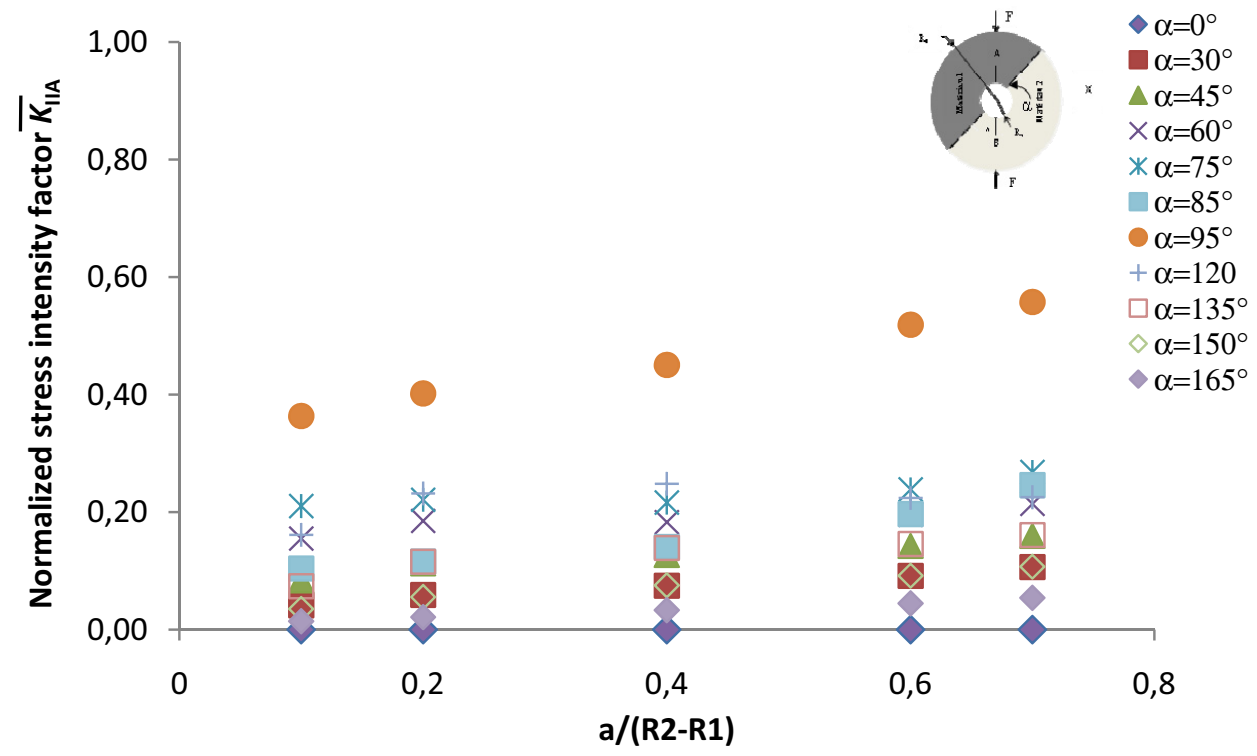

Fig. 11. Evolution of normalized stress intensity factor in mode II (shear) at crack tip A. 


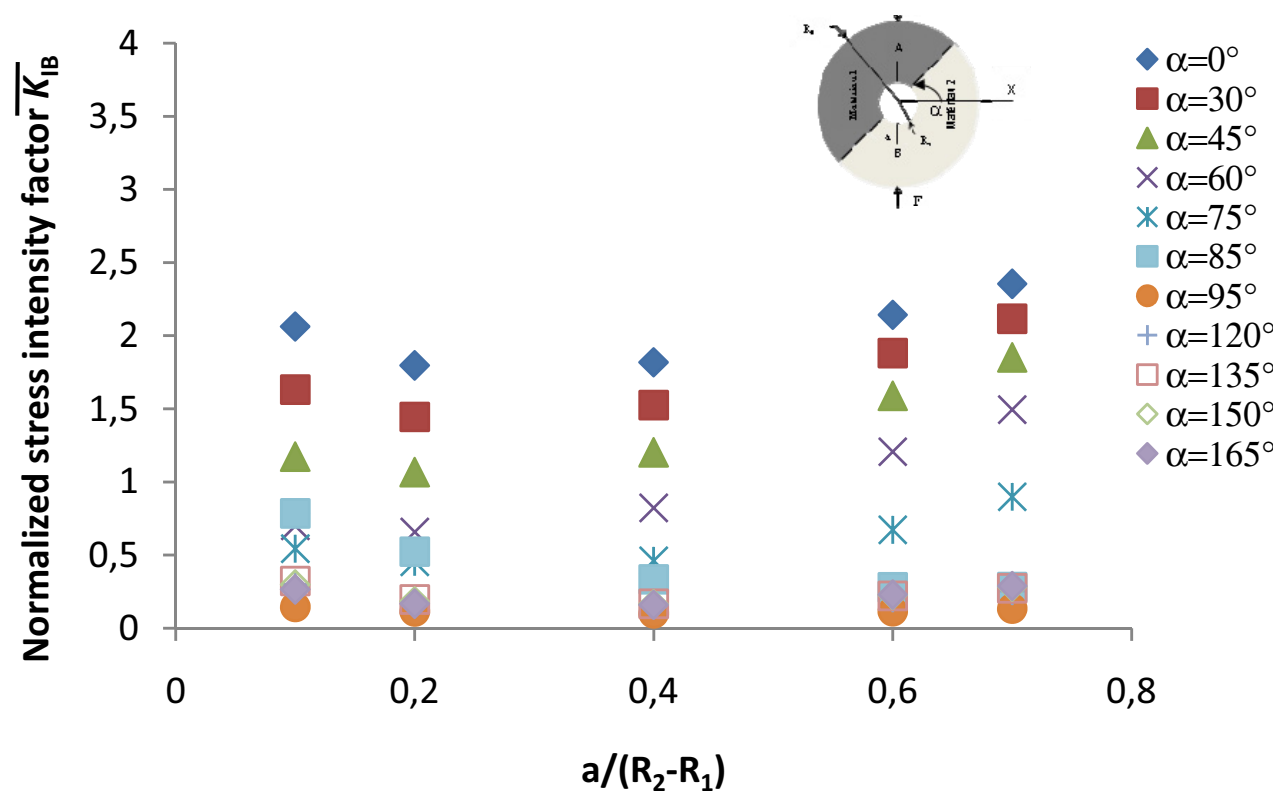

Fig. 12. Evolution of normalized stress intensity factor in mode I (opening) at crack tip B.

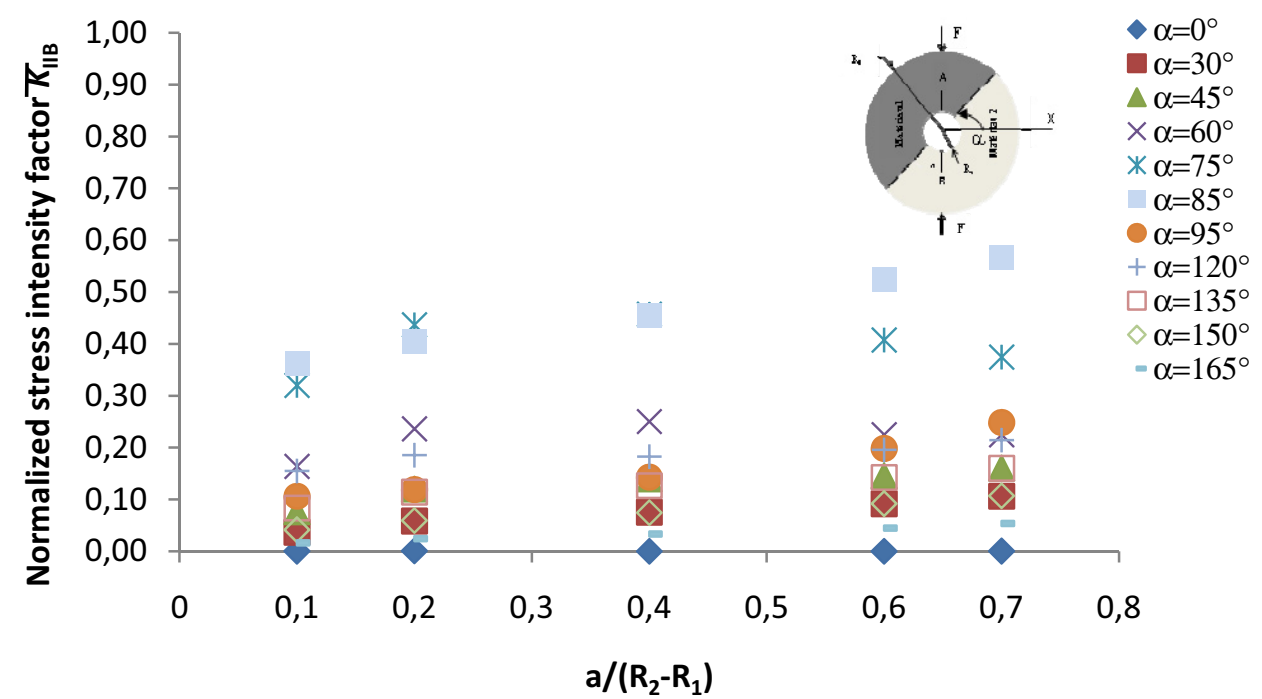

Fig. 13. Evolution of normalized stress intensity factor in mode II (shear) at crack tip B.

Figures 12 and 13 show the same factors for the crack tip B. In each case, the SIF data decrease when the interface angle increases. A minimum appears more or less pronounced for a normalized crack length of 0.4 .

Figures 14 and 15 show the evolution of normalized equivalent stress intensity $\bar{K}_{\text {eqA }}$ and $\bar{K}_{\text {eqB }}$.

For inclination angles $\alpha$ between $0^{\circ}$ and $85^{\circ}$ (Fig. 14), we notice that normalized equivalent $\operatorname{SIF} \bar{K}_{\text {eqA }}$ data are very small and present an overlap when the crack tip A grows in the material with lower Young modulus. For the case of crack tip B which is located in the material 2, the values of normalized equivalent stress intensity factors $\bar{K}_{\text {eqB }}$ (Fig. 15) are very high and their evolution is on progress especially for crack lengths $a /\left(R_{2}-R_{1}\right) \geq 0.4$. When $\alpha$ varies between $95^{\circ}$ and $165^{\circ}$, the crack tip $\mathrm{A}$ is located in the most stiffener material (aluminium) and $\bar{K}_{\text {eqB }}$ values are close and quite small.

Also, it is very interesting to represent in Figures 16 and 17 the evolution of the same stress intensity factors $\bar{K}_{\text {eqA }}$ and $\bar{K}_{\text {eqB }}$ with inclination angle $\alpha$.

Figures 16 and 17 show the both zones of crack tip evolution where the interface is marked by a vertical dashed line which corresponds to $\alpha=90^{\circ}$. For the case where $\alpha$ is below $90^{\circ}$ (Fig. 16), the crack tip $\mathrm{A}$ is located in the material 1 and the stress intensity factor values $\bar{K}_{\text {eqA }}$ are low and look the same until $\alpha$ is near $85^{\circ}$ where the tendency to decrease is more significant. Near $\alpha=90^{\circ}$, we notice that $\bar{K}_{\text {eqA }}$ increases due to the higher stiffness. This evolution is even more significant with crack size $a /\left(R_{2}-R_{1}\right)$. Figure 17 shows the opposite evolution for crack tip B. 


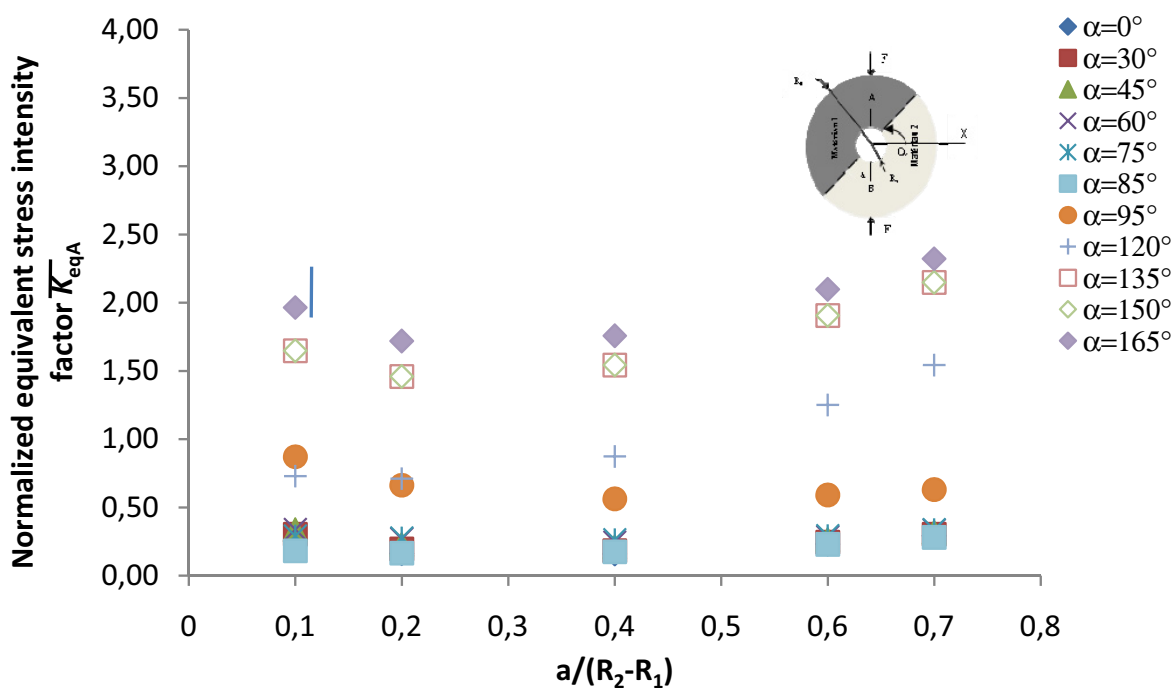

Fig. 14. Evolution of normalized equivalent stress intensity factor at crack tip A.

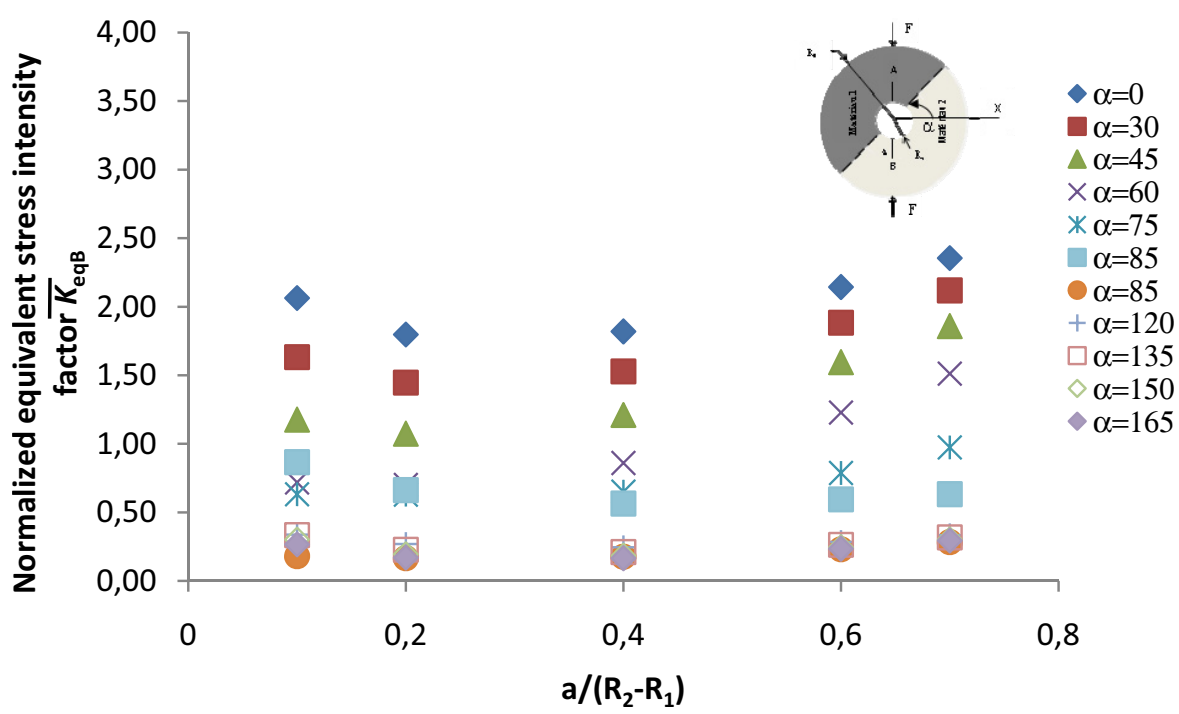

Fig. 15. Evolution of normalized equivalent stress intensity factor at crack tip B.

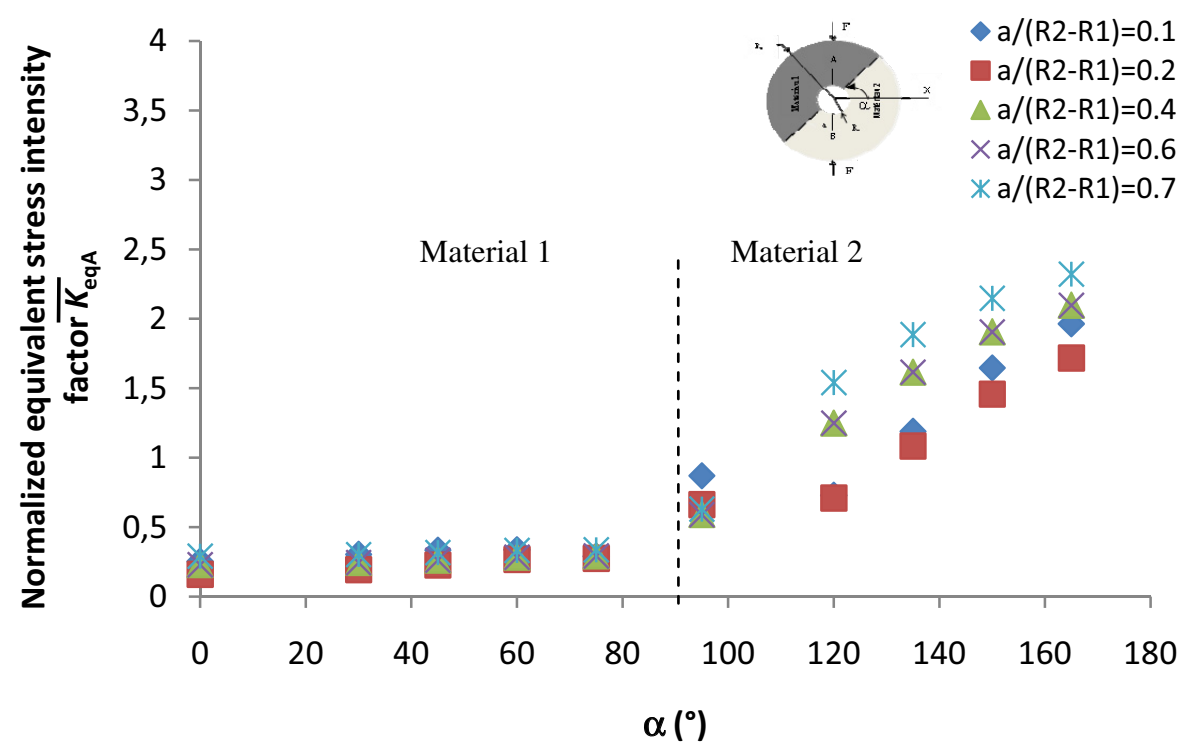

Fig. 16. Effect of interface angle $\alpha$ on normalized equivalent stress intensity factor at crack tip A. 


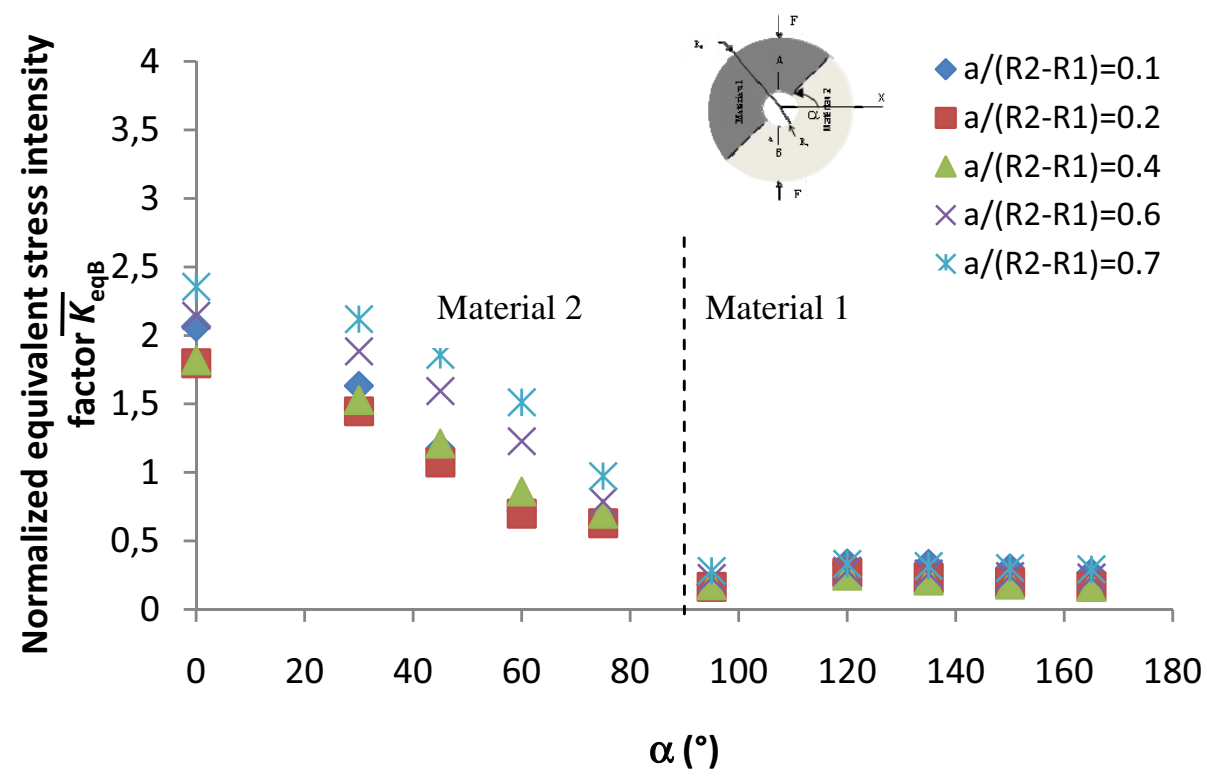

Fig. 17. Effect of interface angle $\alpha$ on normalized equivalent stress intensity factor at crack tip B.

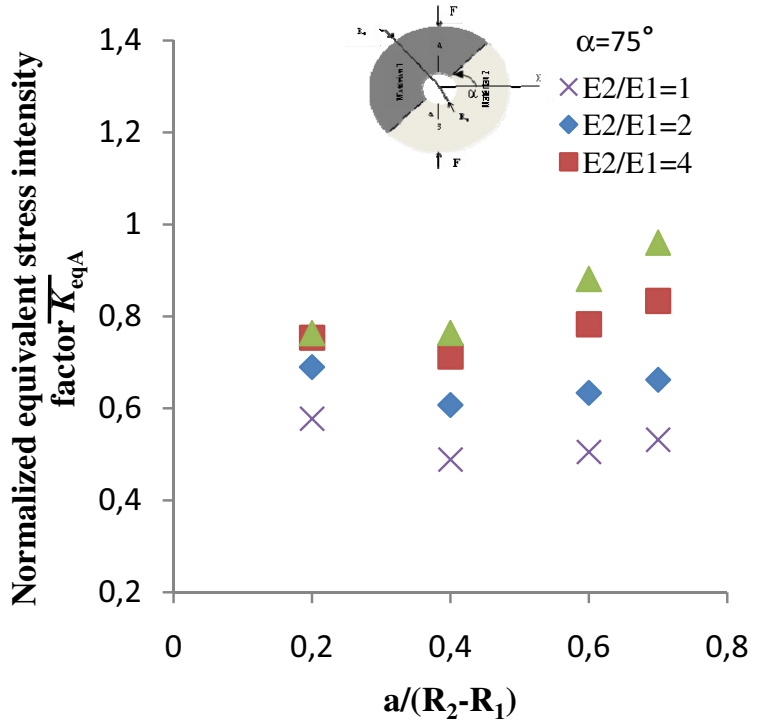

(a)

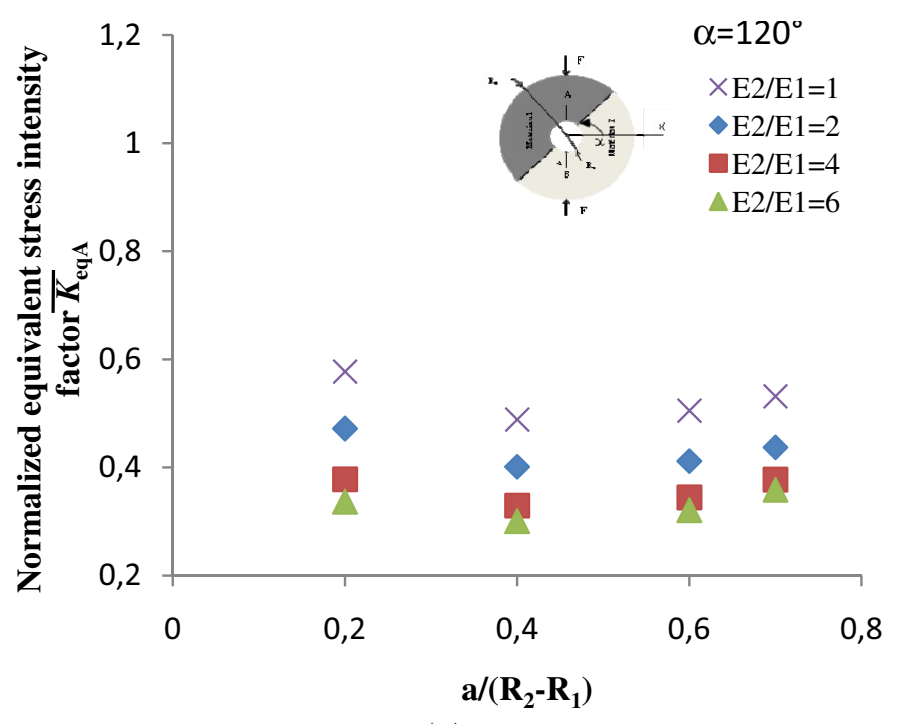

(b)

Fig. 18. (a) Evolution of normalized equivalent stress intensity factor with crack length and material ratio $E_{2} / E_{1}$ for $\alpha=75^{\circ}$. (b) Evolution of normalized equivalent stress intensity factor with crack length and material ratio $E_{2} / E_{1}$ for $\alpha=120^{\circ}$.

This is due to fact where the crack tip is located in the weakest material.

\subsubsection{Influence of material properties on stress intensity factors}

The influence of material properties on normalized stress intensity factors has been study for $\alpha=75^{\circ}$ and $120^{\circ}$, and material ratio $E_{2} / E_{1}=2,4$ and 6 (see Figs. 18a and $\mathrm{b}$ ). For the case where $\alpha=75^{\circ}$, the graphs seem very close for any material ratio.

When $\alpha=120^{\circ}$, the crack tip A is located in the stiffer material, $\bar{K}_{\text {eqA }}$ increases more significantly as crack length ratio increases. The growth tendency has been presented in the paper of Madani et al. [13] for the case of bi-material plate with an edge crack in term of energy release rate variation with crack length and material ratio $E_{2} / E_{1}$.

Finally it is interesting to study the variation of $\bar{K}_{\text {eqA }}$ according to $E_{2} / E_{1}$ for different values of $\alpha$ and for a fixed crack length $a /\left(R_{2}-R_{1}\right)=0.4$ (Fig. 19). In this figure, the corresponding values to $\alpha=90^{\circ}$ have been calculated using Excel program based on node displacements obtained by finite element method and Equations (1) to (9). The results show that some of the graphs follow a growth evolution when $\alpha>90^{\circ}$ and the crack tip $\mathrm{A}$ is located in the 


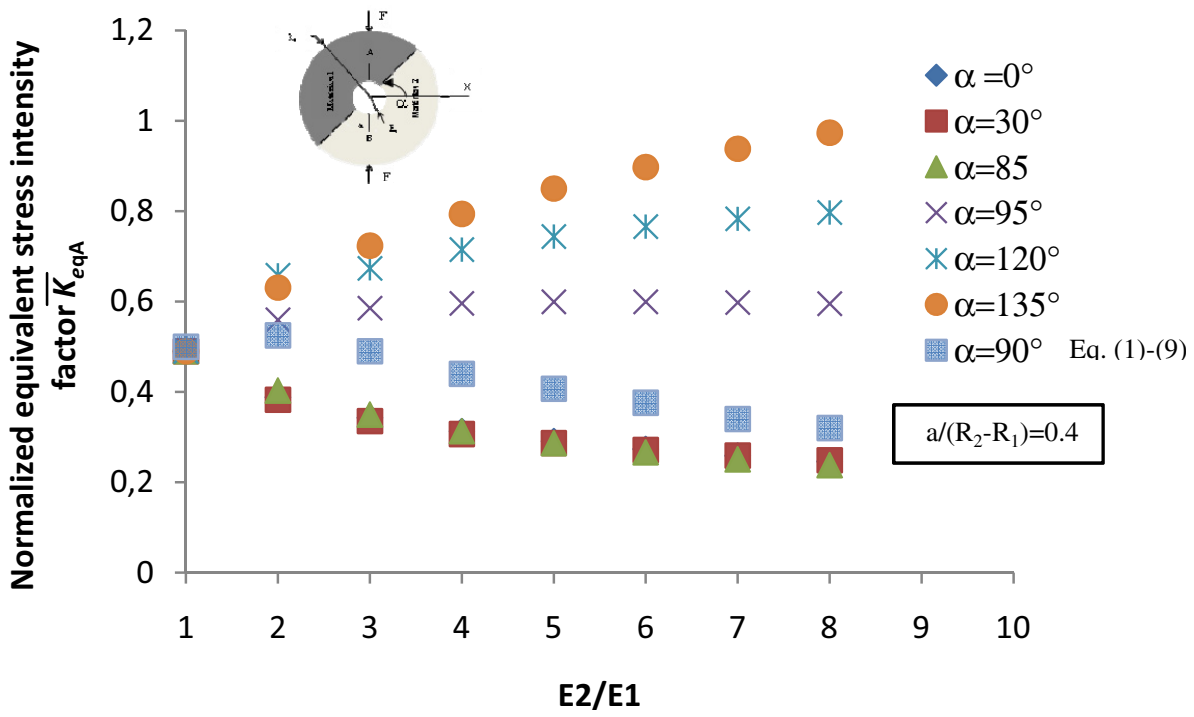

Fig. 19. Variation of normalized equivalent stress intensity factor at crack tip $\mathrm{A}$ with material ratio $E_{2} / E_{1}$ and $\alpha$ for $a /\left(R_{2}-R_{1}\right)=0.4$.

stiffer material. For $\alpha \leq 90^{\circ}$, the $\bar{K}_{\text {eqA }}$ values decrease especially when $\alpha=0^{\circ}, \alpha=30^{\circ}$ and $\alpha=85^{\circ}$ where the $\bar{K}_{\text {eqA }}$ values are very close.

Most of the numerical results show that compression test on the cracked ring specimen formed by bi-material presents a continuity of normalized equivalent stress intensity factors evolution in term of orientation angle, stiffness ratio and normalized crack length. Then, it is much easier to characterize the fracture strength of cracked interface.

The fracture toughness of a brittle biomaterial can be evaluated from Figure 19 according to Young's modulus ratio $E_{2} / E_{1}$ and inclinaison angle $\alpha$. Due to the fact that we are in elastic case, fracture toughness is given by multiplying $K_{\text {eqA }}$ by the ratio $F_{\mathrm{c}} / F_{\text {comp }}$ where $F_{c}$ is the critical load and $F_{\text {comp }}$ the computing load.

\section{Conclusion}

This study has extended the mismatch effect analyses for the mixed mode of fracture as the published results were only concerning the case of opening mode. In this paper, it has been noticed that the mismatch effect can be present in the mixed mode of fracture for both cases such as: bi-material plates with inclined crack under tensile loading and bimaterial cracked ring specimen subjected to compression loading.

The results show that the mismatch effect depends on the crack length for both opening mode and on the crack inclination angle i.e. the bimodality crack loading. This effect is characterized by the tendency to decrease the equivalent SIF in mixed mode when the crack tip is located in the weakest material. Hence, we confirm the results obtained by Kazi Tani et al. [15] and experimentally by Cirello et al. [12] who have used the same specimen in the first mode of fracture with different width ratios.
In order to develop toughness tests for cracked bimaterial specimens, we have studied the mismatch effect by using a cracked bi-material ring. The choice of this specimen is based on the fact that its manufacture is easy and cheaper. Furthermore, its shape allows us to change the bimodality by a simple rotation of the interface to loading direction.

The results show that it can be easy to obtain specimen calibration function in order to determine the critical stress intensity factor. The low cost of the test specimen and the execution celerity can allow easily getting the intrinsic curve of the interface fracture for bi-material.

\section{References}

[1] F. Erdogan, Stress distribution in a non homogeneous elastic plane with cracks, J. Appl. Mech. 30 (1963) 232237

[2] J.R. Rice, G.C. Sih, Plane Problems of Cracks in Dissimilar Media, ASME J. Appl. Mech. 32 (1965) 418423

[3] M.L. Williams, The stresses around a fault or crack in dissimilar media, Bull. Seismological Sot. Amer. 49 (1959) 199-404

[4] J. Dundurs, Discussion of edge bonded dissimilar orthogonal elastic wedges under normal and shear loading, J. Appl. Mech. 36 (1977) 650-652

[5] M. Comninou, The interface crack, J. Appl. Mech. 44 (1977) 631-636

[6] T.C. Wang, P. Stahle, Stress state in front of a crack perpendicular to bimaterial interface, Eng. Fract. Mech. 59 (1998) 471-485

[7] P.R. Marur, H.V. Tippur, A strain gage method for determination of fracture parameters in bi-material systems, Eng. Fract. Mech. 64 (1999) 87-104

[8] C. Bjerken, C. Persson, A numerical method for calculating stress intensity factors for interface cracks in bimaterials, Eng. Fract. Mech. 68 (2001) 235-246 
[9] T. Ikeda, C.T. Sun, Stress intensity factor analysis for an interface crack between dissimilar isotropic materials under thermal stress, Int. J. Fract. 111 (2001) 229-249

[10] K. Yilan, L. Hua, Investigation of near tip displacement fields of a crack normal to and terminating at a bimaterial interface under mixed mode loading, Eng. Fract. Mech. 69 (2002) 2199-2208

[11] F. Jiang, Z.L. Deng, J.F. Wel, Crack propagation resistance along strength mismatched bimetallic interface, J. Mater. Eng. Performance 13 (2004) 93-98

[12] A. Cirello, B. Zuccarello, On the effects of a crack propagating towards the interface of a bimaterial system, J. Eng. Fract. Mech. 73 (2006) 1264-1277

[13] K. Madani, M. Belhouari, B.B. Bouiadjra, B. Sereir, M. Benguediab, Crack deflection at an interface of alumina/metal joint: A numerical analysis, Comput. Mater. Sci. 38 (2007) 625-630

[14] D. Ouinas, B.B. Bouiadjra, B. Sereir, J. Vina, Influence of bi-material interface on kinking behavior of a crack growth emanating from notch, Comput. Mater. Sci. 41 (2008) 508-514
[15] N. Kazi Tani, T. Tamine, G. Pluvinage, Numerical evaluation of energy release rate for several crack orientation and position to the bi-material interface plates, Damage and fracture Mechanics, Failure Analysis of Engineering Materials and Structures, Springer 2009, pp. 445-454

[16] J.R. Rice, Elastic fracture mechanics concepts for interface crack, J. Appl. Mech. 55 (1988) 98-103

[17] C.L. Tan, Y.L. Gao, Treatment of bi-material interface crack problems using the boundary element method, Eng. Fract. Mech. 36 (1990) 919-932

[18] E. Ergun, K. Aslantas, S. Tasgetin, Effect of crack position on stress intensity factor in particle-reinforced metalmatrix composites, Mech. Res. Comm. 35 (2008) 209-218

[19] E. Madenci, I. Guven, The finite element method and applications in engineering using ANSYS, Springer Edition, 2006

[20] R.E. Peterson, Stress concentration factor, John Wiley and Sons, New York, 1974 